\title{
Mediciones y predicciones en influenza
}

\author{
Jorge Jiménez de la Jara
}

\author{
Measurements and predictions in influenza
}

$\mathrm{E}$ 1 planeta Tierra vive su segundo año de pandemia de influenza AH1N1, iniciada formalmente en California el 17 de abril de 2009 después de la identificación de dos casos en niños, pero declarada pandemia por la Organización Mundial de la Salud (OMS) mientras ocurrían los casos de México, hacia fines del mismo mes ${ }^{1}$.

Como en toda pandemia, especialmente en una época de globalización intensa de las comunicaciones y de las conductas en un mundo aún muy desigual, surgieron velozmente todo tipo de reacciones sociales, tecnocráticas, de políticas e intervenciones destinadas a conocer mejor el fenómeno y poder dominar sus ominosas consecuencias. El fantasma de la Gran Influenza de 1918, casi un siglo después y con varias pandemias, aunque menores en impacto de morbi-mortalidad en el intertanto, sigue presente en la memoria colectiva y genera acciones. A este contexto, se suma la alerta para una eventual pandemia de influenza aviar, cuyos términos de enfrentamiento fueron recogidos en un Plan Nacional elaborado el año 2005 por el Ministerio de Salud ${ }^{2}$. Sobre estas nuevas situaciones la opinión pública y grupos de diversa naturaleza se pronuncian a medida que se desenvuelven los acontecimientos, con grados variables de intensidad, intencionalidad y compromiso ${ }^{3}$.

El Ministerio de Salud, como Autoridad Sanitaria, generó rápidamente sus comités de acción y un Grupo de Expertos que le apoyó en el análisis y toma de decisiones al más alto nivel. El primer caso detectado en Chile y comprobado por medios de laboratorio ocurrió el 17 de mayo. Se trataba de una mujer joven, proveniente de un período de vacaciones en República Dominicana. Desde ese momento y hasta la fecha (marzo de 2010), el Ministerio de Salud ha emitido con regularidad y consistencia reportes sobre el estado del brote de influenza en el país. De acuerdo a esos informes y con distintos mecanismos de verificación la autoridad declara que:

"Han ocurrido durante 2009, 368.129 casos compatibles con la definición de caso sospechoso de influenza pandémica; se confirmaron a través de RPC especifica en tiempo real 12.302 casos de infección por influenza pandémica (H1N1). Se entregaron 634.450 tratamientos antivirales gratuitos en el sector público y privado".

"Entre los casos confirmados, 1.622 presentaron una
IRA grave, con una mediana de edad de 32 años. El 32\% de los casos tenía antecedentes de enfermedad crónica $y$ entre los casos positivos con RPC hay 155 personas fallecidas"4.

De la casuística nacional, se han publicado pocos trabajos. Uno de ellos muy específico sobre los síntomas gastrointestinales ${ }^{5}$ y otro sobre las características de la epidemia en un centro asistencial privado ${ }^{6}$.

\section{Medir para predecir y prevenir}

La epidemiología nace como una ciencia de la observación de las enfermedades de las personas que ocurren en poblaciones y comunidades. El primer y más obvio evento para medir es la mortalidad y sus causas, el indicador más certero que podemos tener. Después viene el conteo de los enfermos, pero aquí surgen los problemas propios de las debilidades de los métodos, las incertidumbres de la realidad o la efectividad de los casos. Serán también factores importantes en el conocimiento de la epidemia la fortaleza de los medios para comprobar el diagnóstico, los criterios clínicos y de laboratorio, la notificación de los eventos y su acopio en oficinas centrales que procesen los datos, los comparen con el denominador de la población total y lleguen a conclusiones expresadas en proporciones o tasas?.

El virus influenza, de alta contagiosidad, cuyo genoma varía en el tiempo, genera brotes, epidemias y pandemias según su capacidad de ataque. El caso de la nueva influenza de 2009 desató gran incertidumbre a su inicio y activó el sistema de vigilancia global que se había instalado a contar del año 2000 en los CDC de E.U.A. y la OMS, reforzado después de los ataques a las torres gemelas de New York y los temores al bioterrorismo. Se discutió mucho si esta conducta había sido excesiva, una sobre reacción producto de una suerte de paranoia epidemiológica, o había sido lo adecuado frente a un nuevo virus. No faltaron las interpretaciones conspirativas en las cuales oscuros poderes interesados en vender antibióticos y vacunas estarían manipulando desde bambalinas. Pura epidemiología política, como en los mejores tiempos de las pestes medievales.

Uno de los primeros anillos de vigilancia epidemio-
Pontificia Universidad Católica de Chile Departamento de Salud Pública Facultad de Medicina

Correspondencia a: Jorge Jiménez de la Jara jjimenez@med.puc.cl 
lógica son los informes de las autoridades locales, por remotas que sean y las noticias de prensa que aparecen sobre eventos inusuales. En este caso, el día 20 de abril de 2009, el Dr. Scott Dowell del Centro de Detección Global del CDC, cruzó dos informaciones aparentemente no conectadas: dos niños en California que habían contraído una forma extraña de influenza porcina sin tener contacto con animales y el aumento inusual de casos de neumonía grave en adultos jóvenes en la capital de México. Los virus aislados de los niños de California y los pacientes de neumonía de México fueron idénticos y así saltó la alarma de una posible pandemia en su etapa inicial. En esos días se supo que había reportes anteriores desde México (abril 10) que no fueron valorados como verdaderos $^{8}$. El debate internacional científico y de opinión pública se centró en si las autoridades mexicanas habían respondido prontamente para diagnosticar la epidemia y si las medidas habían sido las adecuadas. El Presidente de México se quejó amargamente del abandono y falta de solidaridad de otros países que ilusamente cancelaron vuelos y cerraron fronteras con su nación. Un eminente salubrista de origen mexicano, decano de la tradicional Escuela de Salud Pública de Harvard, argumentó en el sentido contrario a través de la prensa ${ }^{9}$.

El modelo de predicción es importante para poder programar los recursos, tomar decisiones de protección de la población, como el cierre de colegios o instituciones de aglomeración humana (centros comerciales, cines), ir graduando el uso de los instrumentos desde el control de la expansión a la mitigación de la epidemia. Saber predecir es importante también para el uso de terapias antivirales según la gravedad de los casos, y sobre todo para la credibilidad de la autoridad sanitaria que necesita lograr la participación disciplinada de la ciudadanía. En el caso de Chile 2009, la constitución de un comité asesor de expertos, provenientes de la academia, con capacidad de apoyo y vocería ante la opinión pública junto a la participación de una Presidenta de la República que además era médico y epidemióloga, fueron importantes en el comportamiento ejemplar del sistema sanitario y de sus usuarios.

Una vez determinada la estructura molecular y genética del nuevo virus, elaborados los kits para su identificación en muestras de pacientes sospechosos, se inicia lo que podríamos llamar el lento proceso de conteo del número de casos ciertos y sus proyecciones hacia las poblaciones afectadas por la pandemia. Estas pruebas, cuya fidelidad y validez se discute intensamente, no son baratas y las autoridades recomiendan rápidamente basar el recuento en el cumplimiento del protocolo clínico ${ }^{10}$. Además, como sucede en todas las epidemias, es plausible sostener que por cada caso demostrado serológicamente, hay un número de casos clínicos evidentes y otro tanto, mayor habitualmente, de casos subclínicos. Todos ellos, puestos en una pirámide en cuyo ápice están los fallecidos por

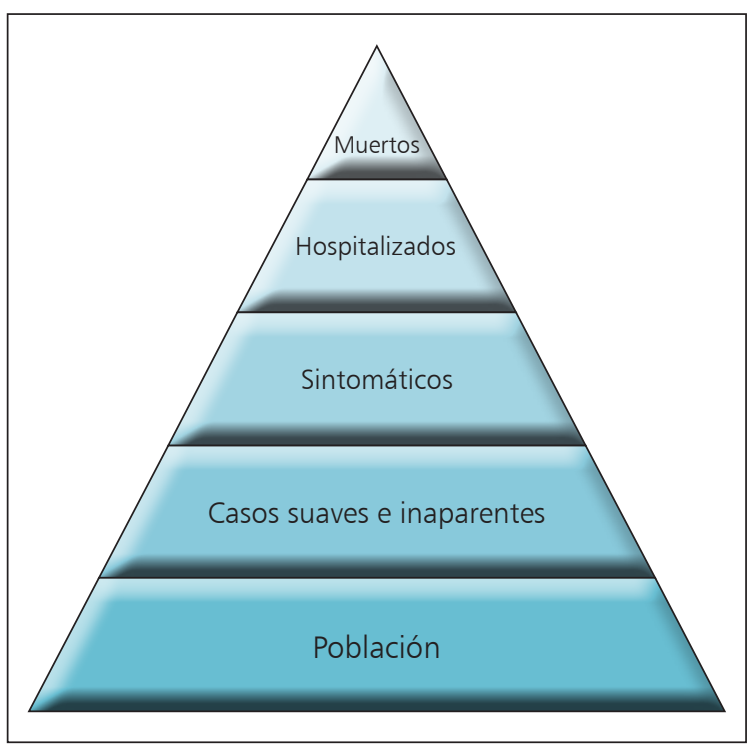

Figura 1. Pirámide de secuencia en la infección por virus influenza.

la enfermedad y en cuya base está la población total de estudio, en este caso el país, constituyen una secuencia de certezas que varían según los métodos de estimación que se use (Figura 1).

La forma como se van relacionando estas cifras entre sí es objeto de estimaciones metodológicas como las que muestran el artículo de M. Canals, publicado en este número de Revista Chilena de Infectología ${ }^{11}$. El autor utiliza una cifra de reproducibilidad (Ro) de entre 1,6 y 2, 2 casos nuevos por caso conocido que, proyectados curvas llamadas de Bland Altman y comparadas con las curvas reales, otorgan una estimación que eleva el número de casos sobe la realidad. De todas formas, las observaciones diarias y su acumulación para el análisis permiten ir estimando la progresión de la epidemia y sacar conclusiones una vez terminado la fase más intensa.

Una encuesta serológica verdaderamente representativa de la población afectada nos dará una aproximación más cercana, cuyas tasas podremos proyectar. La encuesta realizada en el caso de Chile 2009 en la comuna de San Felipe está siendo procesada. Sin embargo, estimaciones preliminares no oficiales suponen que la población infectada y con sintomatología clínica en el país no sería mayor a 4 a 6\%, unos 850.000 (676.000-1.014.000) casos, incluyendo todos los grupos de edad. Esta cifra se acerca bastante al número de tratamientos antivirales efectivamente usados según reportaron los servicios de salud $^{12}$. Una comunicación reciente sobre serología para el virus nuevo de influenza habla de uno de cada tres niños menores de cinco años con anticuerpos presentes entre 2008 y 2009, después del brote en Gran Bretaña ${ }^{13}$.

Es interesante hacer que la pandemia de 1957, reporta- 
da para el caso de Chile por figuras históricas de la salud pública nacional dio tasas de ataque basadas en estimaciones de ausentismo laboral y escolar, más una encuesta de morbilidad en Santiago y los cálculos de la mortalidad y letalidad del brote. Los datos son interesantes y nos dicen que la población joven es la más afectada $-49,2 \%$ bajo 20 años de edad- que los habitantes de poblaciones “callampas", o sea los más pobres, concentran tasas más altas de enfermedad por el hacinamiento. Que la letalidad, siendo baja ( $0,13 \%$ de los enfermos), es muy visible pues los fallecidos que llegaban a los dos únicos cementerios de la ciudad eran entre 50 y 178 en el día de mayor número. Un testigo de la época anotaba que había una "lista de espera" en el Cementerio General muy visible ${ }^{14}$.

En suma, las mediciones y predicciones sobre epidemias y pandemias de influenza son bastante necesarias pero adolecen de las incertidumbres propias de la variabilidad del virus, de su parentesco con generaciones anteriores, de nuestras propias capacidades para medir. Por ello este tipo de desafíos son oportunidades importantes para el desarrollo científico de la infectología, la epidemiología, el buen uso de las vacunas y las políticas sanitarias.

\section{Referencias}

1.- Swine influenza A (H1N1) infection in two children-Southern California, March-April 2009. MMWR Morb Mortal Wkly Rep 2009; 58: 400-2.

2.- MINSAL Chile: Plan Nacional de preparación para una pandemia de influenza, Santiago, 2007.

3.- Jiménez J. Epidemia de influenza 2009, Una lección de solidaridad social, Revista Mensaje, julio 2009, Santiago de Chile.

4.- MINSAL Chile: Influenza pandémica (H1N1) 2009, Reporte de Situación, 16 de Marzo de 2010.

5.- Riquelme A, Álvarez-Lobos M, Pavez C, Hasbun P, Dabanch J, Cofré C, Jiménez J, Calvo M. Gastrointestinal manifestations among Chilean patients infected with novel influenza A
(H1N1) 2009 virus. Gut 2009; 58 (11): $1567-8$.

6.- Torres JP, O’Ryan M, Herve B, Espinoza R, Acuña G, Mañalich J, Chomalí M. Impact of the novel influenza A (H1N1) during the 2009 autumn-winter season in a large hospital setting in Santiago, Chile. Clin Infect Dis 2010; 50 (6): 860-8.

7.- Lilienfeld \& Lilienfeld, Foundations of Epidemiology, Oxford University Press, New York 1980

8.- Mcneil D G. Virus's tangled genes straddle continents, raising a mistery about its origins", The New York Times, May 1, 2009.

9.- Frenk J. Mexico's Fast diagnosis, op-ed New York Times, May 1, 2009.

10.- MINSAL Chile. División de Prevención y Control de Enfermedades, Guía Clínica para el diagnóstico y manejo clínico de casos de Infección por virus Influenza A (H1N1) Fecha: Marzo 2010.

11.- Canals M. Predictibilidad a corto plazo del número de casos de influenza pandémica AH1N1 basada en modelos determinísticos. Rev Chil Infect 2010; 27: 117-23.

12.- Información personal no publicada

13.- Miller E, Hoschler K, Hardelid P, Stanford E, Andrews N, Zambon M. Incidence of 2009 pandemic influenza A H1N1 infection in England: a cross-sectional serological study. Lancet 2010; 375: 1100-8.

14.- Valenzuela G, Horwitz A,Ristori C, Boccardo H, Borgoño J M, Bertin V. Aspectos epidemiológicos de la epidemia de influenza en la ciudad de Santiago de Chile. Bol Of San Pan 1958; 44 (4): 316-29. 